\title{
A Phase II Study of Gefitinib in Patients with Metastatic Melanoma
}

\author{
Sapna P. Patel, Kevin B. Kim, Nicholas E. Papadopoulos, Wen-Jen Hwu, Patrick Hwu, \\ Victor G. Prieto, Menashe Bar-Eli, Maya Zigler, Andrey Dobroff, Yulia Bronstein, Roland L. \\ Bassett, Anna G. Vardeleon, and Agop Y. Bedikian \\ Department of Melanoma Medical Oncology, Pathology, Cancer Biology, Diagnostic Radiology, \\ and Biostatistics and Applied Mathematics, The University of Texas M. D. Anderson Cancer \\ Center, Houston, TX; Oncology Consultants, P.A., Houston, TX
}

\begin{abstract}
Background-Gefitinib is an inhibitor of the epidermal growth factor receptor, which is frequently expressed on both choroidal and non-choroidal melanoma cells. We evaluated the clinical efficacy of gefitinib in patients with metastatic melanoma.
\end{abstract}

Methods-Patients with stage IV or unresectable stage III melanoma and Zubrod performance status $\leq 2$ were eligible. Previous systemic treatment for metastatic disease was required. The dose of oral gefitinib was $250 \mathrm{mg}$ administered daily, and tumor response was evaluated every 6 weeks.

Findings-Forty-six patients with non-choroidal melanoma and six with choroidal melanoma were treated, and 48 were evaluable for response. The median age was 62.5 years. Forty-one patients (79\%) had stage M1c disease. There were no drug-related grade 4 or 5 adverse events, and fatigue was the only grade 3 adverse event that occurred in more than $5 \%$ of patients. Two patients (4\%) had partial responses and 13 patients (27\%) had disease stabilization. The two responders had a median duration of response of 10.9 months. The median progression-free survival overall was 1.4 months and the median overall survival was 9.7 months. Among the patients with sufficient tissues obtained before and 6 weeks after starting gefitinib, there were no notable trends in the changes of the tumoral expression of p-ERK1/2, p-AKT, PAK1 and serum levels of VEGF or IL-8 with treatment.

Interpretation-Gefitinib was well tolerated but had minimal clinical efficacy as a single-agent therapy for unselected patients with metastatic melanoma.

\section{Keywords}

phase II; gefitinib; metastatic melanoma; EGFR

\section{INTRODUCTION}

Because of the poor outcome of patients with metastatic melanoma who are treated with cytotoxic and/or immunotherapy, there is a great interest in a new approach of systemic

Address reprint requests to Agop Y. Bedikian, MD, Department of Melanoma Medical Oncology, Unit 430, The University of Texas M. D. Anderson Cancer Center, 1515 Holcombe Blvd., Houston, TX 77030; Phone: (713) 792-2921; Fax: (713) 745-1046; abedikia@mdanderson.org..

Publisher's Disclaimer: This is a PDF file of an unedited manuscript that has been accepted for publication. As a service to our customers we are providing this early version of the manuscript. The manuscript will undergo copyediting, typesetting, and review of the resulting proof before it is published in its final citable form. Please note that during the production process errors may be discovered which could affect the content, and all legal disclaimers that apply to the journal pertain. 
therapy. Targeted therapies, such as small molecules or antibodies which inhibit receptor protein tyrosine kinases, have received much of the spotlight recently as part of a novel approach of cancer therapy. A growing number of these targeted agents are approved for use in advanced malignancies by the United States Food and Drug Administration each year. Drugs inhibiting the activation of the epidermal growth factor receptor (EGFR), such as erlotinib or cetuximab, have been approved for non-small lung cancer, head and neck squamous cell carcinoma, and colon cancer as a single agent or in combination with other therapies.

Unregulated expression of EGFR is common in neoplastic transformation and has been associated with melanocytic tumor progression (1). Studies with cultured human melanocytes showed that EGFR expression was reduced in the differentiating cells (2). The addition of transforming growth factor (TGF)-alpha to early melanoma cell cultures induced a rapid increase in the intensity of the EGFR signal, suggesting that receptors had been upregulated. EGFR and its ligand, TGF-alpha, are reported to be involved in autocrine growth of melanoma cells (3). In situ analysis of the expression and localization of receptors showed correlation between an increased expression of TGF-2, IGF-1, and EGFR with depth of invasion and metastases in malignant melanoma (4). Ex vivo delivery of suicide genes into melanoma cells using EGFR-specific Fab immunogene resulted in inhibition of the growth of melanoma cells (5). Overexpression of EGF receptor was associated with spontaneous metastases of human melanoma cell line in nude mice (6). Shahbazi et al. found a strong association between a functional polymorphism in the EGF gene and malignant melanoma in the European white population (7). They showed that cells from individuals homozygous for the $61 * \mathrm{~A}$ allele produced significantly less EGF than cells from $61 * \mathrm{G}$ homozygotes or heterozygous A/G individuals. Compared with the A/A genotype, G/ $\mathrm{G}$ was associated with increased Breslow thickness and with risk of malignant melanoma. In addition, expression of EGFR on melanoma cells in patients with metastatic choroidal melanoma was found to be associated with increased capacity to spread to the liver, ability to resist TNF-mediated tumor lysis, and decreased survival (8). Furthermore, there is plenty of evidence that the oncogenic properties of EGFR may be mediated by stimulation of angiogenesis and up-regulation of potent angiogenesis growth factors such as VEGF and IL-8, and blockage of the EGFR can cause down regulation of VEGF and IL-8 expression and inhibit angiogenesis $(9,10)$.

Gefitinib (Iressa ${ }^{\circledR}$ ), an anilinoquinazoline, is a potent and selective inhibitor of the EGFR tyrosine kinase in vitro and in vivo (11). Expression of EGFR by melanoma cells is associated with their ability to metastasize. Thus, we hypothesized that targeted EGFR blockade with the selective inhibitor, such as gefitinib, may be an effective therapeutic agent in patients with metastatic melanoma. To test this hypothesis, we conducted a phase II study of gefitinib in patients with metastatic melanoma. In addition to examining the clinical efficacy, we also evaluated the deactivation of EGFR and its downstream signal pathways as well as antiangiogenic activity after gefitinib treatment by collecting tumor and blood samples from patients.

\section{PATIENTS AND METHODS}

This was an open-labeled, single-arm phase II clinical trial. The protocol for this study was approved by the institutional review board of The University of Texas M. D. Anderson Cancer Center. All patients gave written informed consent before enrollment.

\section{Patient Selection}

Eligible patients had to be at least 18 years old of age and have the Zubrod performance status of 0 to 2, with adequate bone marrow, kidney and liver functions. They were required 
to have histologically confirmed, unresectable stage III or stage IV metastatic melanoma with measurable lesions defined by Response Evaluation Criteria in Solid Tumors (RECIST). Patients with melanoma of cutaneous or mucosal origin must have had received systemic chemotherapy for metastatic disease but should not have had received more than 2 previous cytotoxic chemotherapy regimens, excluding biologicals, vaccines, and hormonal drugs. Patients with metastatic melanoma of choroidal origin could be chemo-naïve or have had received up to 2 previous chemotherapy regimens.

Patients with brain metastases must have had no radiographic evidence of recurrences in the brain for at least 3 months after the complete resection of the brain metastases or must have had asymptomatic brain metastases stable for at least 3 months since whole brain radiation therapy or stereotactic radiosurgery. Patients with a history of wound-healing disorders, advanced coronary disease or with a recent history (within 6 months) of peptic ulcer disease were excluded. Patients who required the concomitant use of phenytoin, carbamazepine, barbiturates, rifampicin, phenobarbital, or St John's Wort were excluded due to interactions with drug metabolism.

\section{Treatment Plan}

All treatments were administered on an outpatient basis. Gefitinib was administered orally at a daily dose of $250 \mathrm{mg}$ until there was evidence of disease progression or unacceptable toxicity or upon patients' withdrawal from the study. A cycle was defined as 3 weeks of treatment.

Ten patients underwent tumor biopsies and blood sample collection before treatment and 6 weeks after the initiation of treatment to assess biological changes associated with gefitinib therapy.

\section{Response Evaluation}

Radiological assessment including computed tomography (CT) and/or magnetic resonance imaging (MRI) scans was performed after every 2 cycles. Clinical responses were evaluated using the international criteria proposed by the RECIST Committee (12). Overall clinical response included both complete and partial responses. The duration of clinical response was measured from the time the clinical response was achieved until the time of the disease progression. The progression-free survival (PFS) and overall survival (OS) durations were measured from the start of treatment.

\section{Toxicity Evaluation}

Adverse events were evaluated and recorded according to the National Cancer Institute's Common Toxicity Criteria version 3.0. Complete blood counts with differentials and serum chemistry panels, including liver function tests and blood urea nitrogen and creatinine levels, were obtained every cycle.

\section{EGFR Receptor and Downstream Kinase Expression}

Tissue samples were stained using the peroxidase-conjugated avidin-biotin method for the following kinase proteins: EGFR, pEGFR, ERK1/2, pERK1/2, AKT, pAKT, SRC, pSRC and PAK1. Four-micrometer sections were serially cut and mounted on plus-coated slides. The samples were deparaffinized by heating the sections at $60^{\circ} \mathrm{C}$ for 1 hour on a slide warmer and washing them 3 times in xylene for 3 to 4 minutes. The tissues were then rehydrated in washes of graded alcohol (two of 100\% ethanol and one each of 95\% and 80\% ethanol) for 1 minute each and of phosphate-buffered saline and distilled water for 5 minutes each. The microwave method was used for antigen retrieval: four 2-minute microwave intervals interspersed with 2-minute incubations of the slides outside the microwave. This 
step was followed by a 30-minute incubation in $0.01 \mathrm{M}$ citrate buffer at $\mathrm{pH} 6.0$ (Antigen Unmasking Solution; Vector Laboratories). Endogenous peroxidase activity was quenched by soaking the slides with $2 \%$ sodium hydrogen peroxide in methanol for 20 minutes. After sections were blocked in a universal blocking serum (Vectastain Elite ABC Kit Rabbit IgG; Vector Laboratories) for 30 minutes, they were incubated overnight at $4{ }^{\circ} \mathrm{C}$ with rabbit antihuman antibody against pERK1/2 (Growth/Proliferation Marker SignalStain Phospho p44/42 MAPK-Thr202/Tyr204 IHC Detection Kit; Cell Signaling Technologies) or with rabbit anti-human antibody against pAKT (Phospho-Akt Ser473 Antibody, IHC Specific [diluted 1:80]; Cell Signaling Technologies). For pSRC and PAK1, sections were incubated overnight with rabbit anti-human antibody against pSRC (Tyr 416 Cell Signaling Technologies, diluted 1:50) and PAK1 (Cell Signaling Technologies, diluted 1:100), respectively. The next day, tissues were incubated with a biotin-labeled secondary antibody and then in avidin/biotinylated enzyme complex (Vectastain Elite ABC Kit Rabbit IgG for pAKT [Vector Laboratories]; Growth/Proliferation Marker SignalStain Phospho p44/42 MAPK-Thr202/Tyr204 IHC Detection Kit for pERK1/2 [Cell Signaling Technologies]) for 30 minutes each. The slides were developed with 3-amino-9-ethylcarbazole (AEC substrate kit SK-4200; Vector Laboratories) and then counterstained with hematoxylin (Vector Laboratories). Positive and negative controls were included.

The stained tissue slides were examined simultaneously by two pathologists and a consensus was reached for the grading of each sample on the basis of the percentage of cells staining positively for pERK1/2, pAKT, pSRC and PAK1. The IHC staining grades were: $0,5 \%$ or fewer positive cells; $+1,6-25 \%$ positive cells; $+2,26-75 \%$ positive cells; and +3 , greater than $75 \%$ positive cells.

\section{Blood biomarker Analysis}

Protein levels of VEGF and IL-8 in serum collected from patients were quantified by ELISA assay utilizing a Quantikine Immunoassay kit (R\&D Systems, Minneapolis, MN), according to the manufacturer's protocol. The concentration of VEGF and IL-8 from each sample was calculated based on a standard recombinant protein curve.

\section{EGFR Mutation Analysis}

DNA was extracted from paraffin-embedded verified tumor samples. Polymerase chain reaction was performed forward and reverse on the short arm of chromosome 7 for exons 18-21, the location of EGFR.

\section{Statistical Analysis}

The primary objective of this study was to determine the response rate of gefitinib. The target response rate for gefitinib was $15 \%$. A response rate of 5\% or less was considered ineffective, and treatment with gefitinib would be discontinued.

The study was conducted using the two-stage design proposed by Green and Dahlberg (13). Twenty-five patients were planned to be treated with gefitinib during the first stage of the study. If no patient responded to gefitinib, then the study would be terminated, and gefitinib would be declared ineffective. If 1 to 5 partial responses were observed among the patients treated during the first stage, then 27 more patients would be added during the second stage. However if 6 or more patients responded out of the initial 25 patients, the treatment would be considered active, and the study would be terminated without extension to the second stage. If 52 patients were enrolled, and 6 or fewer patients responded to the therapy, gefitinib would be declared ineffective against metastatic melanoma. However, if 7 or more patients responded to the therapy, gefitinib would be considered efficacious. 
If the probability of rejecting a good therapy was 5\%, then a total sample size of 52 patients would yield $80 \%$ power using the response rates stated above. Data analysis was performed using SAS or S-Plus, as appropriate.

\section{RESULTS}

\section{Patient Characteristics}

From December 2003 to August 2006, a total of 52 (46 non-choroidal and 6 choroidal primary) patients were enrolled and treated with gefitinib because one patient achieved a partial response among the 25 patients in the first stage. The characteristics of the patients are listed in Table 1. Forty-six patients had metastatic melanoma of cutaneous or mucosal origin, and six patients had metastatic melanoma of choroidal origin.

\section{Treatment}

The 52 patients received a total of 176 cycles of gefitinib (median, two cycles per patient; range, one to fourteen). Three patients could not complete 1 cycle of treatment due to the patient withdrawal $(n=1)$, rapid disease progression $(n=2)$. One of the patients who had rapid disease progression died during the first cycle. Five patients were treated more than 6 months.

\section{Clinical Efficacy}

Among the 52 patients enrolled, 50 patients were evaluable for response. Two patients were inevaluable for response: one patient decided to withdraw from the study after 4 days of treatment, and the other committed suicide before the first response evaluation. There were no complete responses and two (4\%) partial responses. Thirteen patients (26\%) had disease stabilization for at least 6 weeks. Disease control, including both response and disease stabilization, was achieved in 8 patients (16\%) for at least 3 months, and in 6 patients (12\%) for at least 6 months.

One of the responders had a stage IV (M1c) melanoma with metastatic lesions in the subcarinal lymph node and subcutaneous tissues in the shoulder with elevated serum lactate dehydrogenase (LDH) level of 658 IU/L (normal range 313-618 IU/L). Her tumor responded after 2 cycles of treatment, but her treatment was discontinued after 4 cycles due to grade 3 transaminitis. Nonetheless, her duration of response persisted with a progressionfree survival of 12.1 months. The other responder, a patient with primary choroidal melanoma, also had stage IV (M1c) disease involving the liver and mesenteric lymph nodes with a normal LDH level. Her tumor also responded after 2 cycles and she continued treatment with gefitinib for a total of 12 cycles before coming off study for progressive disease, This patient had a progression-free survival of 9.7 months.

Among all treated patients, the median progression-free survival was 6 weeks (Fig. 1), and the median overall survival duration was 4.6 months (range, 0.8-33.6+ months, Fig. 2).

\section{Toxicity}

Table 2 enlists adverse events. All 52 treated patients were evaluable for toxicity. No grade 4 adverse events were observed. Fatigue was the only grade 3 adverse events that occurred in more than $5 \%$ of the patients, and it was reversible upon discontinuation of treatment. There were no grade 3 hematologic toxicities. 


\section{Correlative studies}

To correlate gefitinib therapy with target modulation, we evaluated the change in EGFR expression before treatment and after 6 weeks of treatment. Ten patients gave consent for paired tumor biopsy and blood collection for correlative studies to evaluate EGFR expression modulation and its downstream signal pathways. Table 3 lists the paired biopsies and serum samples and their relative expression levels of proteins and protein kinases where sufficient samples were available. Overall, there were no notable trends in the tissue level expression of ERK1/2, pERK1/2, AKT, pAKT, SRC, pSRC, and PAK1 with gefitinib therapy. EGFR surface expression was also assessed on 8 patients at baseline and at 6 weeks (Table 4) but no trends were noted. Additionally, serum levels of soluble VEGF and IL-8 showed no significant trends before and during treatment (Table 5).

The presence of activating mutations in EGFR predicts response to gefitinib in patients with non-small cell lung cancer (14-15). We analyzed tumor tissue on 13 patients, including the tumor samples of the 2 responders, for the presence of EGFR mutations. None of the tumor samples from the nonresponders contained EGFR mutation. The tumors of the 2 responders were initially found to harbor 2 missense mutations apiece in the hot spot exons of EGFR with C-> T and G->A changes in exons 19 and 21. However, the presence of the mutation was unable to be confirmed in 5 serial sequencing analyses in the both samples.

\section{DISCUSSION}

This study was designed to evaluate the clinical activity of gefitinib in patients with metastatic melanoma on the bases of preclinical studies implicating the role of EGFR in melanoma progression. We showed in this trial that gefitinib at a daily dose of $250 \mathrm{mg}$ as a single agent, although well tolerated, did not render any meaningful clinical benefits to patients with metastatic melanoma, especially to those whose primary disease was of cutaneous origin. In patients with metastatic melanoma of choroidal origin, there was one response among 6 treated patients, and its early clinical benefit in this population merits a further investigation.

The minimal clinical activity of gefitinib in patients with metastatic melanoma is similar to those of many other targeted drugs, such as thalidomide, bevacizumab, sorafenib and temsirolimus (16-19). These results suggest several possibilities. Patients with advanced melanoma may have tumor cells that proliferate and survive on many separate redundant signal pathways. Indeed, recent data demonstrates that the majority of cutaneous melanomas harbor activating mutations in the mitogen-activated proliferation kinase (MAPK) pathway. Nearly $59 \%$ of these mutations occur in the BRAF gene and another $20-30 \%$ occurs in the $N R A S$ gene (20-24). A recent meta-analysis confirmed these findings in over 8,000 melanoma cell lines and primary resected cutaneous melanomas (25). Similarly, the majority of uveal melanomas $(\sim 80 \%)$ harbor mutations in G-alpha protein subunits upstream of this pathway (26). The presence of these mutations leads to constitutive activation of the MAPK pathways and uncontrolled cellular growth and proliferation. As a result, tumors with these mutations would be refractory to blockade of the upstream EGFR with a receptor tyrosine kinase inhibitor such as gefitinib. Gefitinib monotherapy will be insufficient to induce apoptosis in these cases. Moreover, melanoma cells may rely on other signal pathways such as c-met or insulin-like growth factor for resistance to EGFR therapy (27-30). Constitutive activation of the MAPK pathway may also explain why no consistent changes were noted in downstream protein expression levels or in serum VEGF or IL-8 levels.

In an attempt to identify molecular characteristics of the 2 responders which contributed to their clinical benefit to treatment with gefitinib, we sequenced EGFR to look for activating mutations. The initial mutations found were $\mathrm{C}->\mathrm{T}$ and G->A changes in exons 19 and 21. 
Repeated sequencing to validate these findings unfortunately yielded wild-type EGFR in both patients 5 times. Several reasonable explanations exist for these findings. One possibility involves the heterogeneity of melanoma cells within the same lesion. Validation was performed using laser-capture microdissection to ensure as precise repeated tumor tissue sequencing as possible. Additionally, these particular base-pair changes have been previously reported as artifact as a result of reagent insufficiency (31).

Although we do not advocate the use of gefitinib in patients with metastatic melanoma in general, it will be very interesting to test its clinical activity in those with tumor lesions containing either EGFR mutation or gene amplification as their tumors are more likely to be addicted on the signals originated from the EGFR aberration. However, EGFR mutations in cutaneous melanoma appear to be absent in a small patient series (32). In addition, little is known about gene amplification in these tumors and uveal melanoma tumors. In retrospect, EGFR inhibition may be most beneficial in patients with wild-type $B R A F$ and NRAS whose downstream MAPK pathway is reliant upon EGFR activation and signaling. Recent data using BRAF inhibitors in patients with a mutated BRAF gene show promise in extending the progression-free survival in these patients (33). This signifies the importance of identifying relevant predictive markers and appropriate treatment populations in the success of targeted drugs for this devastating disease.

In conclusion, gefitinib has a minimal clinical activity in unselected patients with metastatic melanoma. However, the combination of gefitinib with other targeted drugs or cytotoxic chemotherapeutic drugs may worth a further exploration, only after convincing scientific rationale and preclinical activities are established in this patient population. In addition, the clinical efficacy of gefitinib in patients with melanoma lesions containing EGFR mutation/ gene amplification should be evaluated to pursue a personalized melanoma therapy.

\section{Acknowledgments}

Funding AstraZeneca and National Cancer Institute grant CA16672.

\section{REFERENCES}

1. de Wit PE, Moretti S, Koenders PG, et al. Increasing epidermal growth factor receptor expression in human melanocytic tumor progression. The Journal of investigative dermatology. 1992; 99(2):16873. [PubMed: 1629628]

2. Real FX, Rettig WJ, Chesa PG, Melamed MR, Old LJ, Mendelsohn J. Expression of epidermal growth factor receptor in human cultured cells and tissues: relationship to cell lineage and stage of differentiation. Cancer research. 1986; 46(9):4726-31. [PubMed: 3015394]

3. Gordon-Thomson C, Mason RS, Moore GP. Regulation of epidermal growth factor receptor expression in human melanocytes. Experimental dermatology. 2001; 10(5):321-8. [PubMed: 11589729]

4. Slominski A, Ross J, Mihm MC. Cutaneous melanoma: pathology, relevant prognostic indicators and progression. British medical bulletin. 1995; 51(3):548-69. [PubMed: 7552081]

5. Ohtake Y, Chen J, Gamou S, et al. Ex vivo delivery of suicide genes into melanoma cells using epidermal growth factor receptor-specific Fab immunogene. Jpn J Cancer Res. 1999; 90(4):460-8. [PubMed: 10363586]

6. Huang TS, Rauth S, Das Gupta TK. Overexpression of EGF receptor is associated with spontaneous metastases of a human melanoma cell line in nude mice. Anticancer research. 1996; 16(6B):355763. [PubMed: 9042221]

7. Shahbazi M, Pravica V, Nasreen N, et al. Association between functional polymorphism in EGF gene and malignant melanoma. Lancet. 2002; 359(9304):397-401. [PubMed: 11844511] 
8. Ma D, Niederkorn JY. Role of epidermal growth factor receptor in the metastasis of intraocular melanomas. Investigative ophthalmology \& visual science. 1998; 39(7):1067-75. [PubMed: 9620065]

9. Bancroft CC, Chen Z, Yeh J, et al. Effects of pharmacologic antagonists of epidermal growth factor receptor, PI3K and MEK signal kinases on NF-kappaB and AP-1 activation and IL-8 and VEGF expression in human head and neck squamous cell carcinoma lines. International journal of cancer. 2002; 99(4):538-48.

10. Perrotte $\mathrm{P}$, Matsumoto T, Inoue K, et al. Anti-epidermal growth factor receptor antibody C225 inhibits angiogenesis in human transitional cell carcinoma growing orthotopically in nude mice. Clin Cancer Res. 1999; 5(2):257-65. [PubMed: 10037173]

11. Wakeling AE, Guy SP, Woodburn JR, et al. ZD1839 (Iressa): an orally active inhibitor of epidermal growth factor signaling with potential for cancer therapy. Cancer research. 2002; 62(20):5749-54. [PubMed: 12384534]

12. Therasse P, Arbuck SG, Eisenhauer EA, et al. New guidelines to evaluate the response to treatment in solid tumors. European Organization for Research and Treatment of Cancer, National Cancer Institute of the United States, National Cancer Institute of Canada. Journal of the National Cancer Institute. 2000; 92(3):205-16. [PubMed: 10655437]

13. Green SJ, Dahlberg S. Planned versus attained design in phase II clinical trials. Statistics in medicine. 1992; 11(7):853-62. [PubMed: 1604065]

14. Kim ES, Hirsh V, Mok T, et al. Gefitinib versus docetaxel in previously treated non-small-cell lung cancer INTEREST): a randomised phase III trial. Lancet. 2008; 372(9652):1809-18. [PubMed: 19027483]

15. Mok TS, Wu YL, Thongprasert S, et al. Gefitinib or carboplatin-paclitaxel in pulmonary adenocarcinoma. New England Journal of Medicine. 2009; 361(10):947-57. [PubMed: 19692680]

16. Reiriz AB, Richter MF, Fernandes S, et al. Phase II study of thalidomide in patients with metastatic malignant melanoma. Melanoma research. 2004; 14(6):527-31. [PubMed: 15577325]

17. Varker KA, Biber JE, Kefauver C, et al. A randomized phase 2 trial of bevacizumab with or without daily low-dose interferon alfa-2b in metastatic malignant melanoma. Annals of surgical oncology. 2007; 14(8):2367-76. [PubMed: 17534686]

18. Eisen T, Ahmad T, Flaherty KT, et al. Sorafenib in advanced melanoma: a Phase II randomised discontinuation trial analysis. British journal of cancer. 2006; 95(5):581-6. [PubMed: 16880785]

19. Margolin K, Longmate J, Baratta T, et al. CCI-779 in metastatic melanoma: a phase II trial of the California Cancer Consortium. Cancer. 2005; 104(5):1045-8. [PubMed: 16007689]

20. Davies H, Bignell GR, Cox C, et al. Mutations of the BRAF gene in human cancer. Nature. 2002; 417(6892):949-54. [PubMed: 12068308]

21. Curtin JA, Fridlyand J, Kageshita T, et al. Distinct sets of genetic alterations in melanoma. N Engl J Med. 2005; 353(20):2135-47. [PubMed: 16291983]

22. Goel VK, Lazar AJ, Warneke CL, et al. Examination of mutations in BRAF, NRAS, and PTEN in primary cutaneous melanoma. J Invest Dermatol. 2006; 126(1):154-60. [PubMed: 16417231]

23. Haluska FG, Tsao H, Wu H, et al. Genetic alterations in signaling pathways in melanoma. Clin Cancer Res. 2006; 12(7 Pt 2):2301-2307s.

24. Poynter JN, Elder JT, Fullen DR, et al. BRAF and NRAS mutations in melanoma and melanocytic nevi. Melanoma Res. 2006; 16(4):267-73. [PubMed: 16845322]

25. Hocker T, Tsao H. Ultraviolet radiation and melanoma: a systematic review and analysis of reported sequence variants. Hum Mutat. 2007; 28(6):578-88. [PubMed: 17295241]

26. van Raamsdonk CD, Bezrookove V, Green G, et al. Frequent somatic mutations of GNAQ in uveal melanoma and blue naevi. Nature. 2009; 457(7229):599-602. [PubMed: 19078957]

27. Yeh AH, Bohula EA, Macaulay VM, et al. Human melanoma cells expressing V600E B-RAF are susceptible to IGF1R targeting by small interfering RNAs. Oncogene. 2006; 25:6574-81. [PubMed: 16715137]

28. Larsson O, Girnita A, Girnita L. Role of insulin-like growth factor 1 receptor signalling in cancer. Br J Cancer. 2005; 92:2097-2101. [PubMed: 15956962] 
29. Satyamoorthy K, Li G, Vaidya B, et al. Insulin-like growth factor-1 induces survival and growth of biologically early melanoma cells through both the mitogen-activated protein kinase and betacatenin pathways. Cancer Res. 2001; 61:7318-24. [PubMed: 11585772]

30. Hilmi C, Larribere L, Giuliano K, et al. IGF1 promotes resistance to apoptosis inmelanoma cells through an increased expression of BCL2, BCL-X(L), and survivin. J Invest Dermatol. 2008; 128:1499-1505. [PubMed: 18079751]

31. Marchetti A, Felicioni L, Buttitta F. Assessing EGFR mutations. New England Journal of Medicine. 2006; 354(5):526-8. [PubMed: 16452569]

32. Akslen LA, Puntervoll H, Bachmann IM, et al. Mutation analysis of the EGFR-NRAS-BRAF pathway in melanomas from black Africans and other subgroups of cutaneous melanoma. Melanoma Res. 2008; 18(1):29-35. [PubMed: 18227705]

33. Flaherty K, Puzanov I, Kim KB, et al. Inhibition of Mutated, Activated BRAF in Metastatic Melanoma. New England Journal of Medicine. 2010; 363:808-819. 
Progression-Free Survival

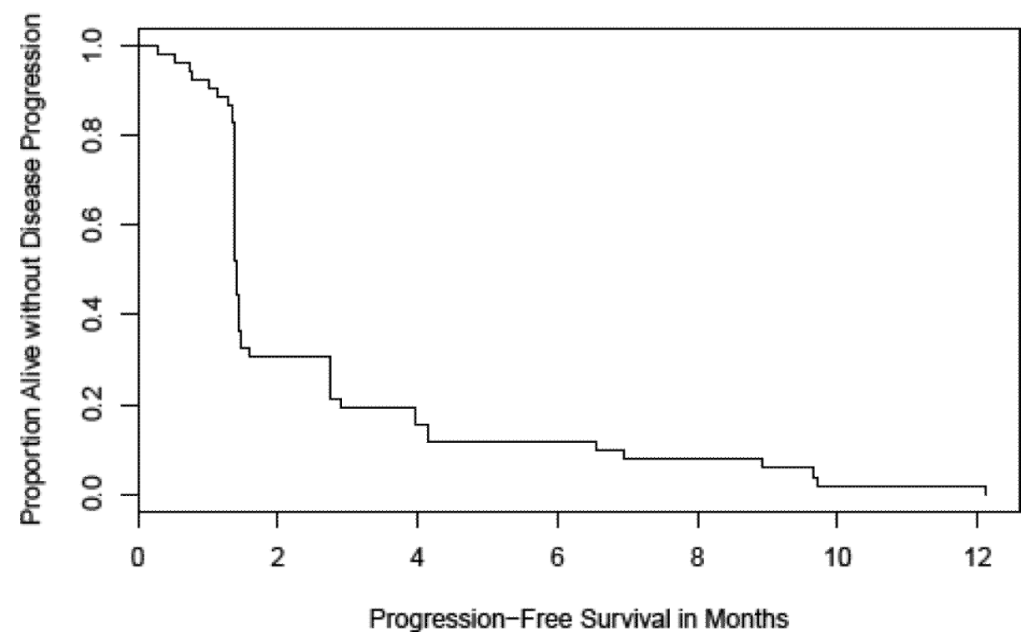

Figure 1.

Progression-free survival - All patients 
Overall Survival

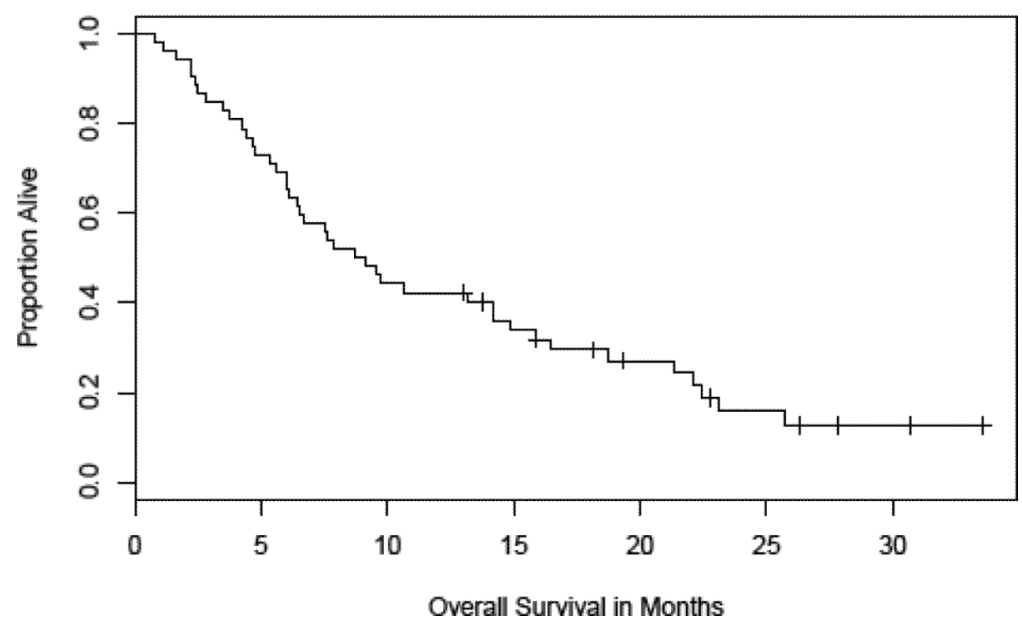

Figure 2.

Overall survival - All Patients 


\section{Table 1}

\section{Patient Characteristics}

\begin{tabular}{|c|c|}
\hline Characteristic & No. Patients (\%) \\
\hline No. of patients & 52 \\
\hline \multicolumn{2}{|l|}{ Site of primary melanoma } \\
\hline Non-choroidal & $46(88)$ \\
\hline Choroidal & $6(12)$ \\
\hline \multicolumn{2}{|l|}{ Sex } \\
\hline Male & $28(54)$ \\
\hline Female & $24(46)$ \\
\hline \multicolumn{2}{|l|}{ Age, years } \\
\hline Median & 62.5 \\
\hline Range & $19-90$ \\
\hline \multicolumn{2}{|l|}{ Zubrod performance status } \\
\hline 0 & $19(36)$ \\
\hline 1 & $30(58)$ \\
\hline 2 & $3(6)$ \\
\hline \multicolumn{2}{|l|}{ Disease stage } \\
\hline III & $4(8)$ \\
\hline IV & $48(92)$ \\
\hline M1a & $0(0)$ \\
\hline M1b & $7(13)$ \\
\hline M1c & $41(79)$ \\
\hline \multicolumn{2}{|l|}{ Serum lactate dehydrogenase level } \\
\hline Normal & $26(50)$ \\
\hline > Upper limit of normal & $23(44)$ \\
\hline \multicolumn{2}{|l|}{ Prior treatment } \\
\hline None (for metastatic disease) & $4(8)$ \\
\hline Isolated limb perfusion & $0(0)$ \\
\hline Hepatic artery chemoembolization & $2(4)$ \\
\hline Biochemotherapy & $20(38)$ \\
\hline Biotherapy & $22(42)$ \\
\hline Chemotherapy & $47(90)$ \\
\hline Interferon-alfa therapy (adjuvant) & $13(25)$ \\
\hline \multicolumn{2}{|l|}{ Site of metastases } \\
\hline Dermis/subcutaneous tissue & $17(33)$ \\
\hline Lymph nodes/soft tissue & $30(58)$ \\
\hline Lung & $31(60)$ \\
\hline Liver & $25(48)$ \\
\hline Bone & $8(15)$ \\
\hline Brain & $1(2)$ \\
\hline Other visceral organs & $15(29)$ \\
\hline
\end{tabular}

Melanoma Res. Author manuscript; available in PMC 2012 August 1. 
Table 2

Grade 3 or 4 Toxicities Observed with Gefitinib Treatment (Number of patients with toxicity; percentage in parentheses)

\begin{tabular}{lll}
\hline Toxicity (n=52) & Grade 3 & Grade $\mathbf{4}$ \\
\hline Hematologic & $0(0)$ & $0(0)$ \\
Neutropenia & $0(0)$ & $0(0)$ \\
Anemia & $0(0)$ & $0(0)$ \\
Thrombocytopenia & & \\
Non-Hematologic & $3(6)$ & $0(0)$ \\
Fatigue & $2(4)$ & $0(0)$ \\
Infection & $1(2)$ & $0(0)$ \\
Dyspnea & $1(2)$ & $0(0)$ \\
Nausea & $1(2)$ & $0(0)$ \\
Vomiting & $1(2)$ & $0(0)$ \\
Headache & $1(2)$ & $0(0)$ \\
Skin rash & $1(2)$ & $0(0)$ \\
Diarrhea & $1(2)$ & $0(0)$ \\
Serum AST/ALT elevation & \\
The numbers in parenthesis indicate the percentages of patients.
\end{tabular}




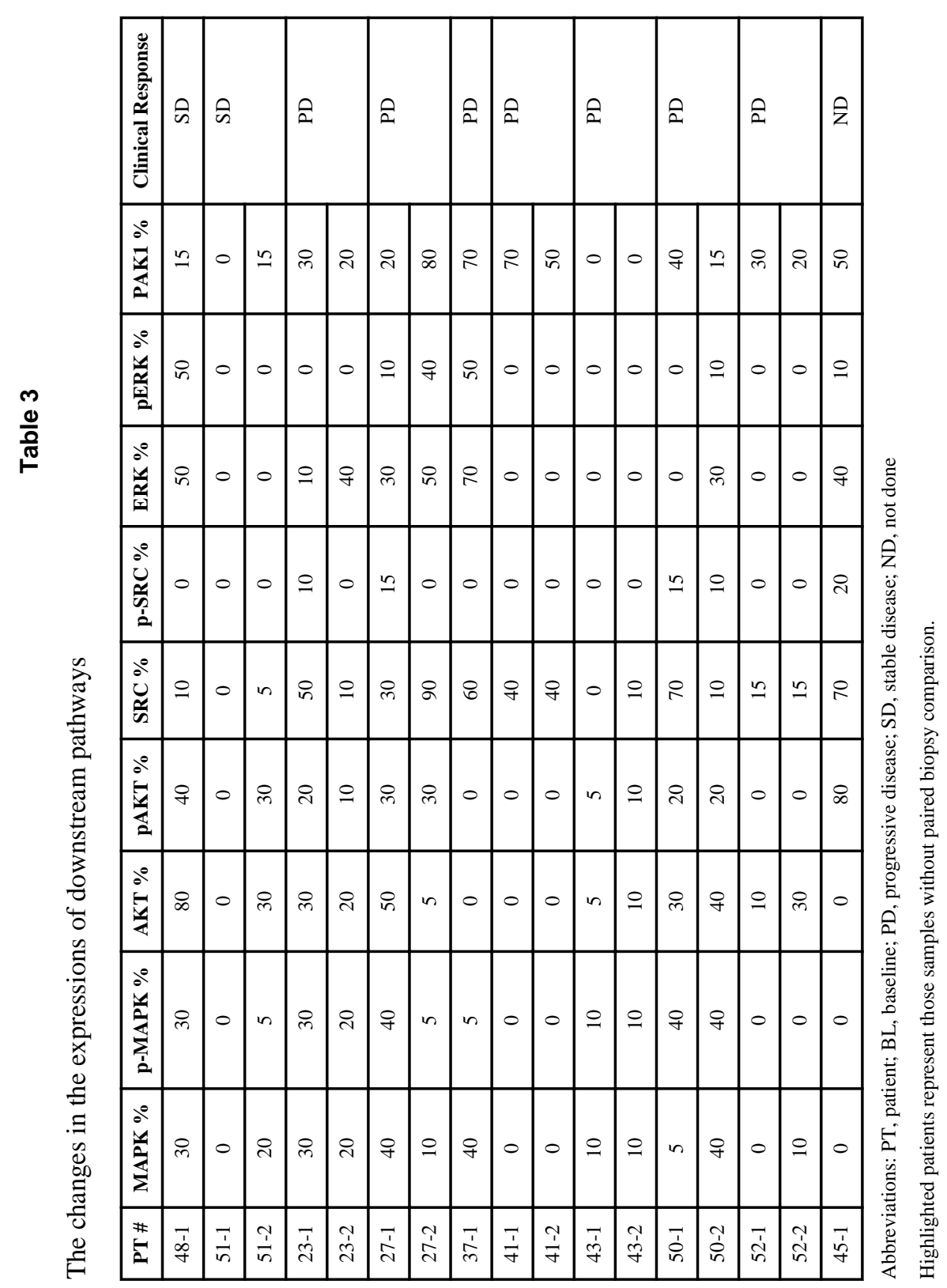

Melanoma Res. Author manuscript; available in PMC 2012 August 1. 


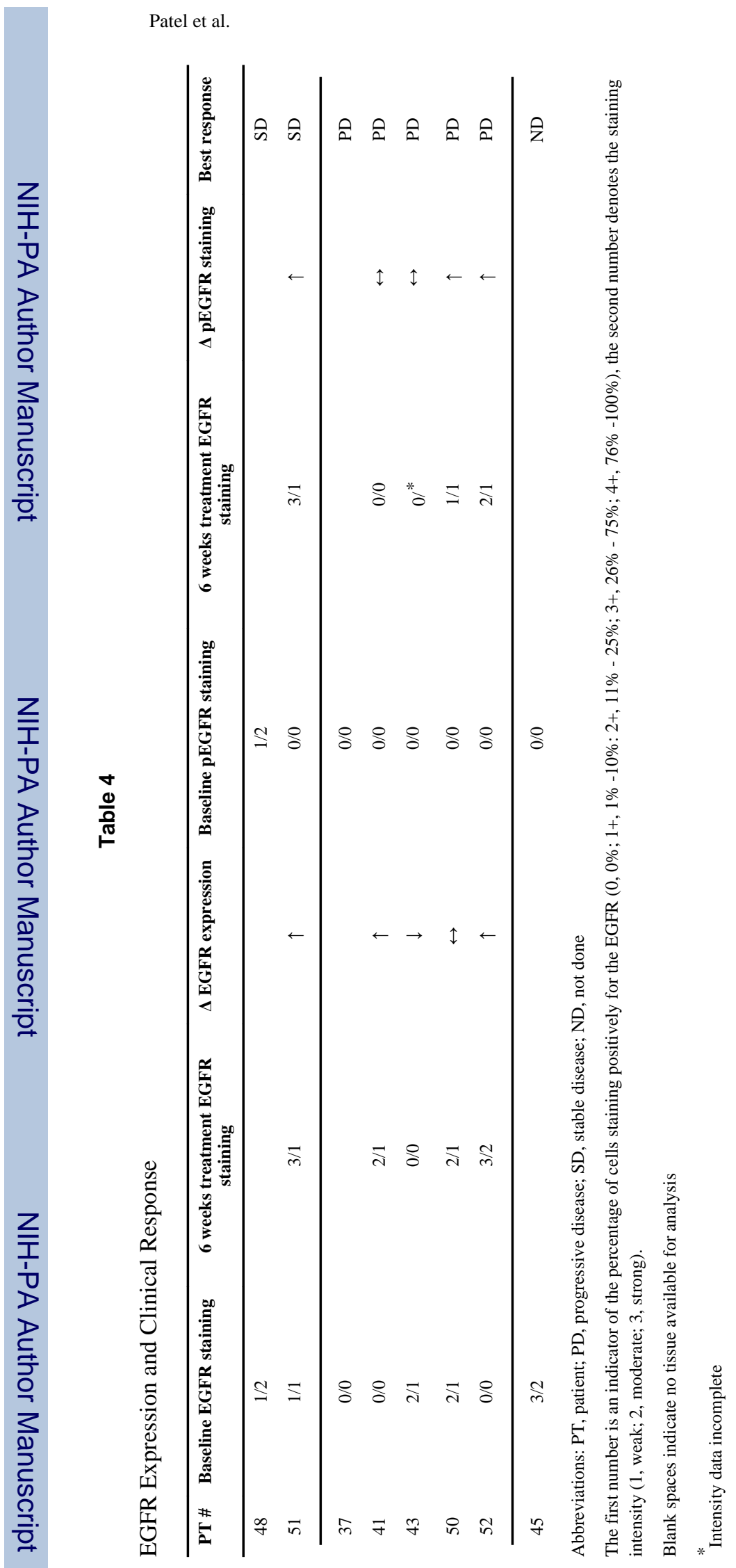

Melanoma Res. Author manuscript; available in PMC 2012 August 1. 


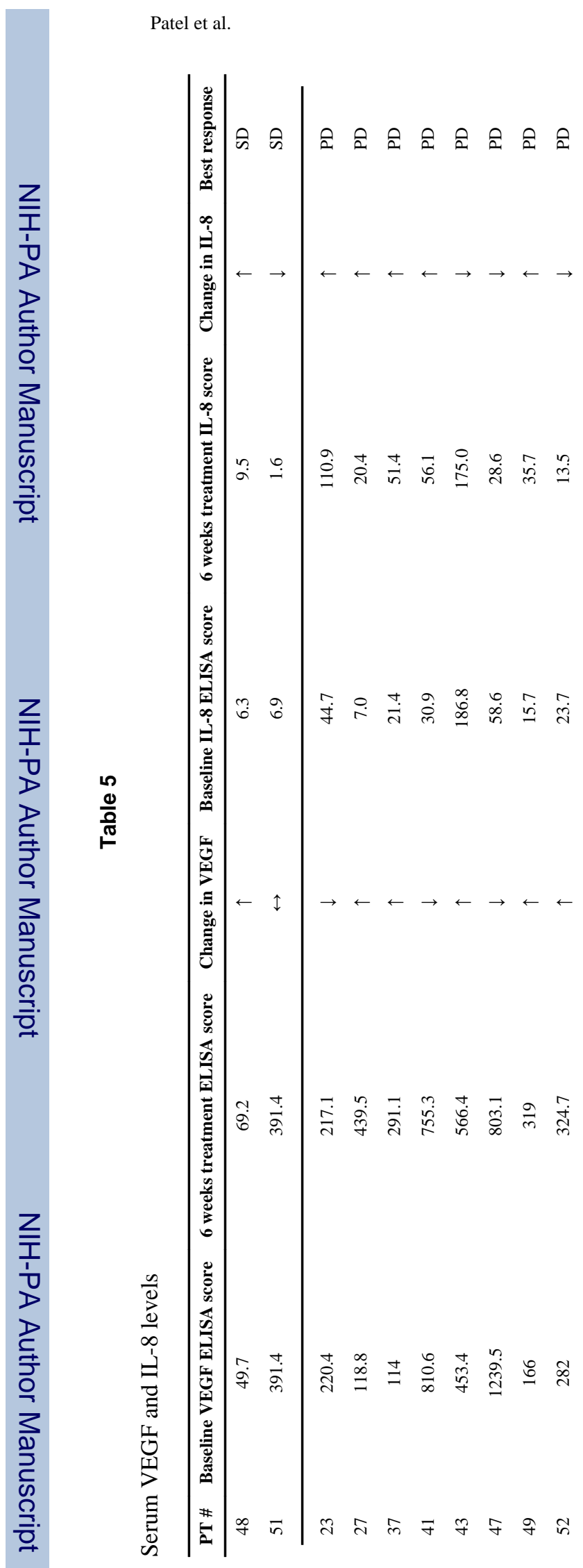

Page 16

Melanoma Res. Author manuscript; available in PMC 2012 August 1. 